\title{
Overview of Rabies in and around Addis Ababa, in Animals Examined in EHNRI Zoonoses Laboratory Between, 2003 and 2009
}

\author{
Abraham Ali*, Fasil Mengistu', Kedir Hussen', Garoma Getahun', Asefa Deressa', \\ Eshetu Yimer ${ }^{2}$ and Kassahun Tafese ${ }^{3}$ \\ ${ }^{1}$ Ethiopian Health and Nutrition Research Institute \\ ${ }^{2}$ African Union /IBAR, Kenya \\ ${ }^{3}$ Addis Ababa Urban Agriculture Extension Core process \\ *Corresponding author: abraalimo@yahoo.com
}

\section{Abstract}

A retrospective data on the number of confirmed animal rabies cases and applied rabies control measures over the period 2003-2009 were collected and analyzed to elucidate the situation of animal rabies in and around Addis Ababa. Over the last seven years, 2517 animals brain tissue samples from Dogs, Cats, Cattle, Horses, Donkeys, Shoats, Hyenas and Monkeys were examined for rabies using Fluorescent Antibody Test. Out of all samples examined, $76.9 \% \quad(n=1936)$ were positive for rabies antigen. A statistically significant difference $\left(X^{2}=34.08(1), P<0.0001\right)$ in sample positivity was observed between male and female dogs, which seems higher proportion in males $79.2 \%$ as compared to $66.9 \%$ in females. Higher proportions of cases were confirmed in stray (86.3\%) than owned dogs $(73.5 \%)$. The difference was highly significant $\left(X^{2}=34.79(1), P<0.0001\right)$. There was highly significant difference $\left(X^{2}=46.73(1), P<0.0001\right)$ in positivity on the vaccination status of dogs. The annual vaccination coverage varies from $1.8-3.8 \%$ during the last seven years. The annual confirmed number of rabies cases dropped in 2005 and 2007 during the last seven years rabies trend in and around Addis Ababa. Statistically significant difference was observed $(F=11.65, P<0.0001)$ in mean number of confirmed rabies cases among 12 calendar months, more number of animal rabies cases was confirmed in summer season.

Keywords: Addis Ababa, Animal, Control, Dog, Positivity, Rabies, Trend

\section{Introduction}

Rabies is a major public-health problem in most of the parts of the developing world, where the dog plays a principal role as a reservoir and transmitter of the disease to humans (WHO, 1992). It is a particular problem in the larger cities of developing countries, with sprawling, impoverished suburbs and high densities of dogs (Eng et al, 1993). 
In Ethiopia it is an important disease that has been recognized for many centuries (Mekonen Fekadu, 1982).The first major outbreaks in dog were reported in many parts of Ethiopia in 1884, especially in the former province of Tigre, Begemder, Gojjam, Wollo and the present Eritrea (Ciotola et al., 1927 cited by Mekonen Fekadu, 1982). Another outbreak of rabies in dogs was also reported in Addis Ababa in August, 1903s, by de Castro (1908).

Like other big cities in developing country, the rabies problem has been greatest in Addis Ababa where the disease had been well established and become endemic (Girma Teferra et al, 2002; Paulos Abebe et al, 2003). The reviewed rabies situation in Ethiopia, revealed that 2172 cases of animal rabies had been confirmed in and around Addis Ababa during 1990-2000, where dogs constituted $89.83 \%$ with the incidence rate of $73.2 \%$ (Eshetu et al., 2002). During 1999-2002 an increasing in canine rabies incidence was observed in the city (Bethlehem Newayeselassie et al., 2004; Paulos Abebe et al, 2003). Moreover, the authors reported that dogs were accounted for almost all the reported human deaths and most cases of human post-exposure treatments in and around Addis Ababa (Eshetu Yimer et al., 2002; Bethlehem Newayeselassie et al., 2004; Paulos Abebe et al, 2003).

Controlling rabies in urban dog populations is seen as a more cost-effective, long-term way to prevent human rabies than reliance on post exposure human treatment (Bogel and Meslin, 1990). In most developed countries several large areas have successfully eliminated canine rabies through legislation, education, and mass vaccination of dogs (Larghi et al., 1988). Cities in poorer countries such as Ethiopia, however, lag behind in control efforts due to various socioeconomic factors and low understanding of the actual trend of the disease. To achieve control, knowledge of the epidemiology of rabies in dog populations has long been recognized as crucial (WHO, 1987).Therefore, this study is intended to elucidate the situation of rabies in Addis Ababa with regard to its incidence in animals, seasonality and control over the period 2003-2009.

\section{Materials and methods}

Study area

The study was conducted in Addis Ababa city administration, the capital of Federal Democratic Republic of Ethiopia. The city covers an area of $530.14 \mathrm{~km}^{2}$ and subdivided into ten sub cites. Addis Ababa lies at an altitude of 2,300 meters above sea level and is a grassland biome, located between $9.03^{\circ}$ North $38.74^{\circ}$ East; latitude and longitude respectively. According to the Urban Ag- 
riculture Extension Core process (2005), the total dog population and number of stray dogs in Addis Ababa are estimated to be 250,000 and 120,000, respectively.

\section{Data Collection}

Animal rabies data in and around Addis Ababa between 2003 and 2009 collected from the annual reports of Zoonoses research team of the Ethiopian Health and Nutrition Research Institute were used for analysis. Only laboratory confirmed animal rabies cases were analyzed to evaluate situation of rabies during the study period. Fluorescent antibody test (FAT) is routinely used diagnostic technique for the conformation of rabies infection in animals from brain tissue samples (Brain stem, Cerebellum and hippocampus). The samples come from two sources: 1) dogs that have bitten people and have been killed or have died; and 2) dogs brought to the rabies laboratory of EHNRI by the public or private veterinarians when they showed symptoms of rabies. Besides, data on the number of vaccinated and eliminated stray dogs between 2003 and 2009 were also gathered from Addis Ababa Urban Agriculture Extension Core process.

Data analysis

The data collected were stored in Microsoft excel spreadsheet and analyzed using SPSS for windows version 12. Descriptive statistics were used to analyze the rate, frequency and proportions. Chi-squire test was used to compare the incidence rate difference between sex, ownership patterns, vaccination status and manner of death. To assess seasonality of rabies incidence, analysis of variance (ANOVA) and F-test were used for statistical significant difference in the mean number of confirmed rabies cases for each of the 12 calendar months.

\section{Result}

Animal rabies

Out of 2517 animal brain tissue samples examined, $76.9 \%$ were positive for Rabies virus. As shown in Table 1, form the total of 1936 rabies laboratory confirmed cases in and around Addis Ababa during 2003-2009, 1724 were dogs, 116 cats, 37 cattle, 13 Horses, 19 Donkeys, 13 sheep \& goats, 7 Hyenas and 7 Monkeys. 
Canine Rabies

From the total of animal samples analyzed dogs represent $89.83 \%$ with the incidence rate of $76.2 \%$. The total numbers of male and female dogs tested were 1727 and 534, respectively. A statistically significant difference $\left(x^{2}=34.08(1)\right.$, $\mathrm{P}<0.0001$ ) in sample positivity was observed between male and female dogs, which seems higher proportion in males $79.2 \%$ as compared to $66.9 \%$ in females. Male dogs were 1.88 times more likely to diagnosed positive than their counterparts $(\mathrm{OR}=1.88)$.

There was statistically significant difference in incidence rate of rabies between stray and owned dogs $\left(X^{2}=34.79(1), P<0.0001\right)$. As shown in Table 2, higher proportions of cases were confirmed in stray $(86.3 \%)$ than owned dogs $(73.5 \%)$. The rate of rabies virus exposure in stray dogs were 2.27 times higher than owned dogs $(O R=2.27)$. Besides, statistically significant difference was also recorded in rabies infection rate between unvaccinated and vaccinated dogs $\left(X^{2}=46.73(1), P<0.0001\right)$; between unvaccinated dogs and dogs with unknown vaccination history $\left(X^{2}=21.02(1), P<0.0001\right)$. Thus, rabies virus infection were more likely to occur in unvaccinated dogs $(O R=13.75)$ when we compared to vaccinated dogs. Moreover, variation in infection rate was also observed between dogs died with out intervention and killed $\left(X^{2}=25.75(1), P<0.0001\right)$, and samples collected from dogs that died with out intervention had 2.20 times more likely to be FAT positive than killed dogs (Table 2).

Animal rabies trend and control measures

Annual number of samples examined between 2003 and 2009 in and Around Addis Ababa varies from 322 to 437 . The annual number of positive cases varied from 231 to 303 , and the annual percentage of samples positive for Rabies virus ranged from $56.3 \%$ to $86.5 \%$. The annual confirmed number of rabies cases dropped in 2005 and 2007, as both vaccination coverage and destruction of stray dogs increased; this trend was especially apparent in the last 7 years (Fig 1). Besides, the graph also indicated that the total number of confirmed animal rabies cases decreased, as did the number of confirmed canine rabies. The routinely applied rabies control measures in Addis Ababa are vaccination of dogs and destruction of stray ones, from 2003-2009 a total of 45217 dogs had been vaccinated meanwhile 72047 had been destructed. As shown in Table 3 the annual vaccination coverage varies from $1.8-3.8 \%$ during the last seven years. 
Seasonality of animal rabies

Statistically significant difference was observed $(\mathrm{F}=11.65, \mathrm{P}<0.0001)$ in mean number of confirmed rabies cases among 12 calendar months in and around Addis Ababa. More number of animal rabies cases was confirmed in June, July, August and September; seasonal increase starting in May and reaching a peak in July (Figure 2 ).

\section{Discussion}

Rabies is well established in Addis Ababa and it is still continue to be major public health problems. Animals are source of rabies infection to humans mainly through biting and they also play pivotal role in maintenance and spread of the virus in Ethiopia. In the present study, the overall percentage of confirmed animal rabies case in and around Addis Ababa (76.9\%) was similar with the findings of Eshetu Yimer et al. (2002) and Paulos Abebe et al. (2003). On the Other hand, lower percentage of positive samples (44\%) was reported in other urban study in Ghana (Belcher et al., 1976).

In agreement with other studies (WHO, 1999 and Girma Teferra et al., 2002), the present study revealed that rabies can infect and be maintained by several different host species, and domestic dogs are most important source of infection to other warm blooded animals due to uncontrolled contact among dogs, other domestic and wild animals in and around Addis Ababa.

The actual numbers of rabid dogs in and around Addis Ababa are under-estimated because many ill dogs are never examined. During the study period dogs constitute more than $89 \%$ of the total samples examined and $76.2 \%$ were positive. This finding is in line with Eshetu Yimer et al. (2002) who reported incidence rate of $73.2 \%$ over the period of 1990 and 2000. It is not surprising to get such figure in rapidly growing cities like Addis Ababa, where large numbers of poorly cared-for or stray dogs are roaming around in the street.

Based on the analysis of risk factors in canine rabies: sex, vaccination status and ownership pattern of the dogs showed significant difference $(p<0.0001)$. Generally, sex does seem to be a risk factor for sample positivity: male dogs had a significantly higher percentage of samples diagnosed positive. Different authors reported the significant variation in positivity to rabies between male and female dogs, with higher proportion of male diagnosed positive than female (Widdowson et al., 2002; Salome et al., 2008). This variation in increased 
risk of acquiring infection may possibly explained by males' fighting over females during there breeding season.

In this study, the higher rabies cases were confirmed in unvaccinated dogs and dogs with unknown vaccination history is in agreement with previous report (Salome et al., 2008). Moreover, significantly higher percentage of positivity was recorded in stray than owned dogs. This implies that stray dogs have pivotal role in maintaining and spread of rabies virus in Addis Ababa and it is in consistent with other reports (Mekonnen Fekadu), 1982; Eshetu Yimer et al., 2002; Paulos Abebe et al, 2003; Bethlehem Newayeselassie et al., 2004).

Animal rabies is well established in and around Addis Ababa, with no decline in the annual number of confirmed rabid dogs for the past 7 years. The confirmed number of rabies cases appeared to decrease in 2005 and 2007. This decrease in incidence may be associated with the reduction of annual number of canine rabies as a result of mass dog vaccination and elimination of stray dogs. There has not been any reduction in the number of rabies cases in spite of vaccination programs, stray dog elimination and other dog population control activities during 2003 to 2009. The actual number of dog population in Addis Ababa is not known. However, based on 2003 estimation of dog population, the annual vaccination rate calculated during the past seven years varies from 1.8$3.8 \%$. These figures may be underestimated due to the lack of data on number of vaccinated dogs by private sectors. However, the finding of this study on annual vaccination rate is below the $70 \%$ recommended to interrupt transmission indicated by WHO (2005).

Although animal rabies cases are reported in different months it was noticed in this study that highest significance figures were reported in June and July. This finding is similar to Mekonnen Fekadu, (1982) that reported rabies outbreak occur annually between July and September. Other authors (Malaga et al., 1979; Ali et al., 2006) also reported the seasonality of rabies and highest incidence in cold season; which is coincide with the mating season of dogs that an important factor may allow the greater contact between animals.

In conclusion, the present study demonstrated that animal rabies incidence is increasing in and around Addis Ababa. Taking into account the seasonal peak of rabies incidence and the majority of animal rabies cases are associated with dogs, all the necessary control measures towards canine rabies that stray dog elimination, mass Immunization campaigns and other dog population control 
activities should be taken in time at a regular base and in coordinated manner.

Table 1: Species of animal examined for rabies using FAT during 2003 and 2009

\begin{tabular}{lcccccccccc}
\hline & \multicolumn{7}{c}{ Species of animal Examined } \\
\cline { 2 - 10 } & Total & Dog & Cat & Cattle & Horse & Donkey & Shoats & Hyena & Monkey \\
\hline Examined & 2517 & 2261 & 132 & 38 & 17 & 21 & 19 & 18 & 11 \\
$(\%)$ & & $(89.83)$ & $(5.24)$ & $(1.51)$ & $(0.68)$ & $(0.83)$ & $(0.75)$ & $(0.72)$ & $(0.44)$ \\
$\begin{array}{l}\text { Positive } \\
\text { (\%) }\end{array}$ & 1936 & 1724 & 116 & 37 & 13 & 19 & 13 & 7 & 7 \\
Percentage & 76.9 & 76.2 & 87.9 & 97.4 & 76.5 & 90.5 & 68.4 & 38.9 & 63.6 \\
\hline
\end{tabular}

Table 2: Characteristics of the 2261 rabies suspicious dogs in and around Addis Ababa from 2003 to 2009

\begin{tabular}{|c|c|c|c|c|c|c|}
\hline $\begin{array}{l}\text { Characteris- } \\
\text { tics }\end{array}$ & $\begin{array}{c}\text { Number of } \\
\text { Samples } \\
\text { Examined }\end{array}$ & $\begin{array}{l}\text { Number } \\
\text { of positive } \\
\text { samples }\end{array}$ & $\begin{array}{c}\text { Percentage } \\
(\%)\end{array}$ & $x^{2}(\mathrm{df})$ & P-Value & $\begin{array}{l}\text { Odds Ratio } \\
\text { (95\% C.I.) }\end{array}$ \\
\hline \multicolumn{7}{|l|}{ Sex } \\
\hline Male & 1727 & 1367 & 79.2 & $34.08(1)$ & $P=0.000$ & $1.88(1.52-2.33)$ \\
\hline Female & 534 & 357 & 66.9 & & & \\
\hline \multicolumn{7}{|l|}{$\begin{array}{l}\text { Ownership } \\
\text { pattern }\end{array}$} \\
\hline Stray & 489 & 422 & 86.3 & $34.79(1)$ & $P=0.000$ & $2.27(1.72-3.00)$ \\
\hline Owned & 1772 & 1302 & 73.5 & & & \\
\hline \multicolumn{7}{|l|}{ Vaccination } \\
\hline \multicolumn{7}{|l|}{ Status } \\
\hline $\begin{array}{l}\text { Unvacci- } \\
\text { nated }\end{array}$ & 1783 & 1336 & 74.9 & $\begin{array}{l}46.73(1) \\
21.02(1)\end{array}$ & $\begin{array}{l}P=0.000 \\
P=0.000\end{array}$ & $\begin{array}{cc}13.75 & (5.19-36.38) \\
0.52 & (0.39-0.69)\end{array}$ \\
\hline Vaccinated & 28 & 5 & 17.9 & & & \\
\hline Unknown & 450 & 383 & 85.1 & & & \\
\hline \multicolumn{7}{|l|}{$\begin{array}{l}\text { Manner of } \\
\text { Death }\end{array}$} \\
\hline Died & 2073 & 1609 & 77.6 & $25.75(1)$ & $P=0.000$ & $2.20(1.61-3.00)$ \\
\hline Killed & 188 & 115 & 61.2 & & & \\
\hline
\end{tabular}


Abraham Ali, et al.

Table 3: Rabies control measures in Addis Ababa (2003-2009)

\begin{tabular}{lccc}
\hline Year & Vaccination & Vaccination coverage & Destruction \\
\hline 2003 & 5894 & 2.4 & 8463 \\
2004 & 6241 & 2.5 & 9035 \\
2005 & 9274 & 3.8 & 10926 \\
2006 & 5716 & 2.3 & 8214 \\
2007 & 8982 & 3.6 & 15963 \\
2008 & 4567 & 1.9 & 11488 \\
2009 & 4543 & 1.8 & 7958 \\
Total & 45217 & 18.1 & 72047 \\
\hline
\end{tabular}

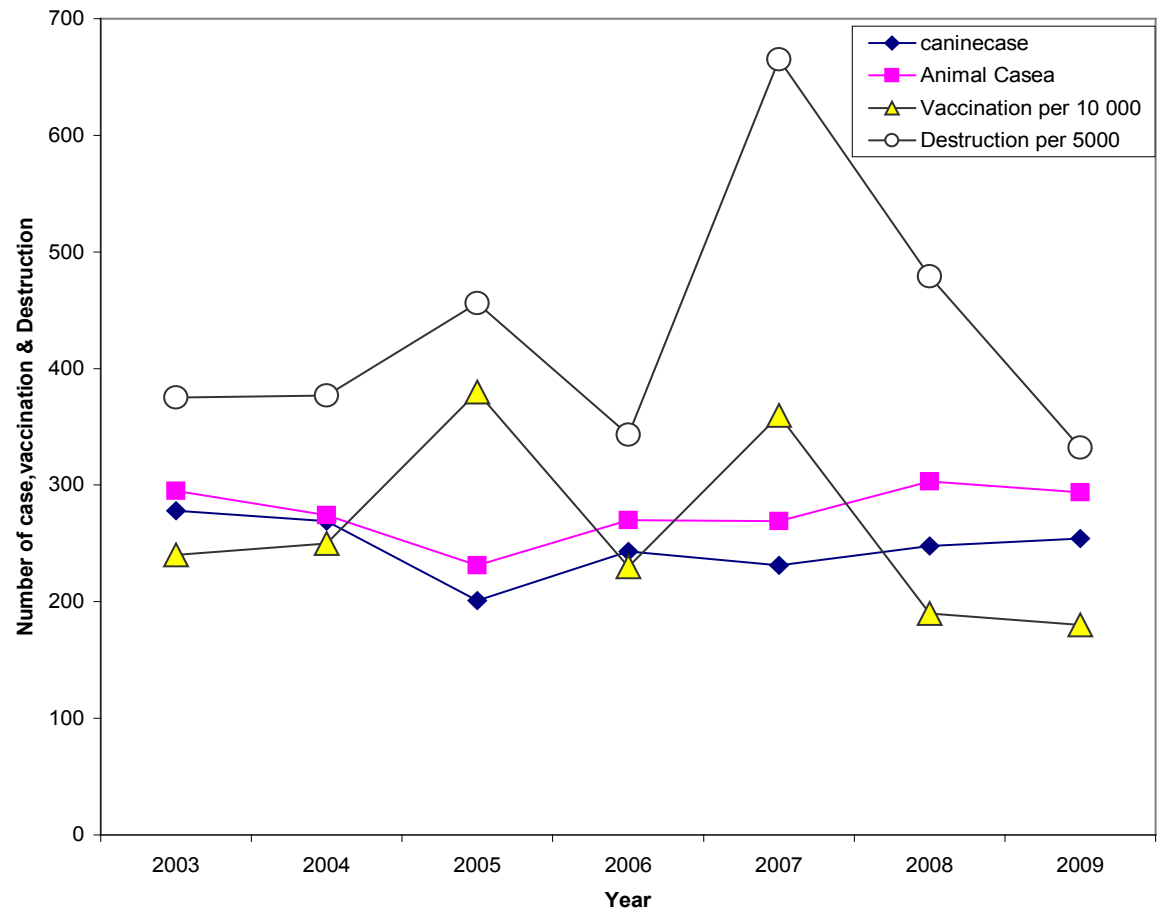

Figure 1: Seven Year Trend of animal and canine rabies in and around Addis Ababa from

20032009 


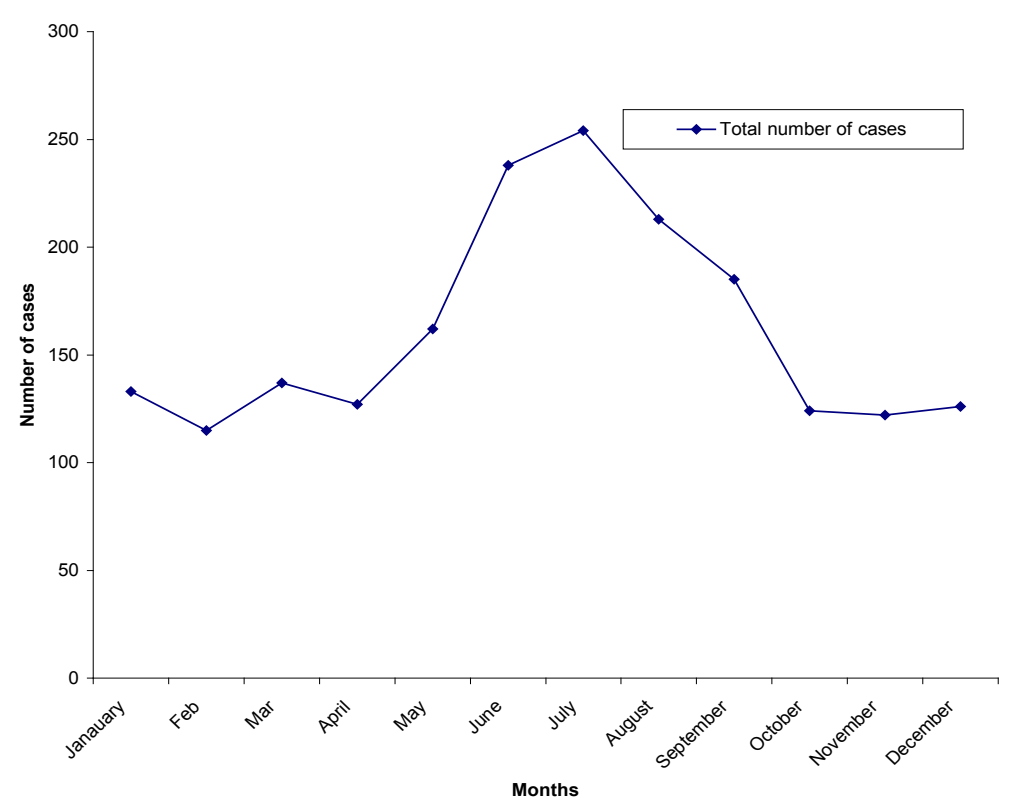

Figure 2: Monthly Distribution of animal rabies in and around Addis Ababa over time 2003-2009

\section{Acknowledgements}

The authors wish to thank the Ethiopian Health and Nutrition Research Institute and Addis Ababa Urban Agriculture Extension Core process for making available the data and reports used in this review.

\section{References}

Abebe, P., Yimer, E., Newayeselassie, B., Bekele, A., Zewde, B. and Beyene, M., 2003. A study on the prevalence of Animals Rabies in Addis Ababa during 1999-2002. Ethiop.Vet. J., 7 (1\&2), 69-77.

Ali, Y., Intisar, S., Wegdan, H. and Ali, E., 2006. Epidemiology of Rabies in Sudan. J. Anm.Vet. Adv., 5(3), 266-270.

Belcher, W., Wurapak, K. and Atuora, C., 1976. Endemic Rabies in Ghana. The Am. J. Trop. Med. Hy., 25(5), 724-729.

Bogel, K. and Meslin, F., 1990. Economics of human and canine rabies elimination: Guidelines for program orientation. Bull World Health Organ., 68, 281-291. 
Ciotola, A. and Alongi, G., 1927. Sull' Epizootia de rabia Sivluppatasi nella Colonia Ertiria Nel Biennio 1925-26. Arch. Ital Sc Med. Colon., 8, 63-76.

de Castro, L., 1908. Medicina vecchiae medicinia nuova in Abissinia. Soc. Geo. Italiana Boll.Ser., 49, 1087.

Eng, T.R., Fishbein, D.B., Talamante, H.E., Hall, D.B., Chavez, G.F., Dobbins, J.G., 1993. Urban epizootic of rabies in Mexico: epidemiology and impact of animal bite injuries. Bull World Health Organ., 71, 615-24.

Fekadu, M., 1982. Rabies in Ethiopia. Amer. J. Epidmiol. 115 (2), 266-273.

Larghi, P., Arrosi, S. and Nakayata, J., 1988. Control of urban rabies, $2^{\text {nd }}$ edition, Kluwer Academic, Boston, USA, pp. 407-22.

Malaga, H., Lopezniet, E. and Gambirazi, C., 1979. Canine Rabies Seasonality. Inter. J. Epidemiol., 18 (3), 243-245.

Newayeselassie, B., Yimer, E., Abebe, P., Bekele, A., Zewde, B. and Beyene, M., 2004. Occurrence of Rabies in Humans and Animals in Addis Ababa in 2001-2002. Ethiop. J. Biol. Sci. 3 (1), 59-67.

Salome, D., Naissengar, S., Mindekem, R., Diguimbye, C., and Niezgoda, M.., 2008. Rabies Diagnosis for Developing Countries. PLoS NegI Trop Dis., 2 (3), 206.

Teferra, G., Yimer, E., and Geyid, A., 2002. Endemic existence of rabies in Ethiopia. Ethiop .Med. J., 40, 163-170.

WHO, 1987. Veterinary public health. WHO guidelines for dog rabies control. World Health Organization (WHO), Geneva, Switzerland.pp.29.

WHO, 1992. Eighth report of the WHO Expert committee on rabies. WHO Technical report series No.79.World Health Organization, Geneva, Switzerland. pp. 84.

WHO, 1999. World survey of rabies No.34 for the year 1998. WHO document WHO/ CDS/CSR/APH/99.6.World Health Organization, Geneva. Switzerland. pp. 3.

WHO, 2005. WHO Expert Consultation on Rabies. WHO Technical Report Series No. 931. World Health Organization (WHO), Geneva, Switzerland.pp.48.

Widdowson, M., Gustavo, J., Sandra, C. and James, M., 2002. Epidemiology of Urban Canine Rabies, Santa Cruz, Bolivia, 1972-1997. Emerg. Infect. Dis. 8 (5), 458461. 
Abraham Ali, et al.

Yimer, E., Newayeselassie, B., Teferra,G., Mekonnen,Y., Bogale,Y., Zewde, B., Beyene,M. and Bekele, A. 2002. Situation of Rabies in Ethiopia: A retrospective study 1990-2000. Eth. J. Health Dev., 16 (1), 105-112. 